\title{
MEMANTINE FOR PREVENTION OF SPINAL CORD INJURY IN A RABBIT MODEL
}

Marek Ehrlich, MD

Erich Knolle, $\mathrm{MD}^{\mathrm{b}}$

Ruxandra Ciovica, $\mathrm{MD}^{\mathrm{a}}$

Peter Böck, MD

Edvin Turkof, $\mathrm{MD}^{\mathrm{a}}$

Martin Grabenwöger, MD

Fabiola Cartes-Zumelzu, MD $^{\mathrm{a}}$

Alfred Kocher, MD

Helmut Pockberger, MD ${ }^{\mathrm{d}}$

W. Christopher Fang, MD

Ernst Wolner, MD

Michael Havel, MDa
Background: This study was conducted to investigate the effect of memantine, a noncompetitive $N$-methyl-D-aspartate receptor antagonist, on the neurologic outcome of spinal cord ischemia after aortic occlusion. Materials and methods: New Zealand White rabbits were anesthetized and spinal cord ischemia was induced for 40 minutes by infrarenal aortic occlusion. Animals were randomly allocated to 3 groups. Group 1 ( $n=8$, control) received no pharmacologic intervention, group $2(n=8)$ received intra-aortic memantine infusion (20 $\mathrm{mg} / \mathrm{kg}$ ) after aortic crossclamping, and group $3(\mathrm{n}=8)$ was treated with systemic memantine infusion $(20 \mathrm{mg} / \mathrm{kg}) 45$ minutes before aortic occlusion. Neurologic status was scored by the Tarlov system (in which 4 is normal and 0 is paraplegia) at $12,24,36$, and 48 hours after the operation. Lumbar spinal root stimulation potentials and motor evoked potentials from lower limb muscles were monitored before, during, and after the operation. After the animals were killed, the spinal cords were studied histopathologically. Results: All potentials disappeared shortly after aortic crossclamping. They returned earlier in both memantinetreated groups than in the placebo group. Histologic examination of spinal cords revealed a few abnormal motor neurons in memantinetreated rabbits but found extensive injury in the control group. At 12 hours the median Tarlov scores were 0 in the control group (group 1), 2 in the intra-aortic memantine group (group $2, P=.001$ versus control), and 3 in the systemic group (group $3, P=.0002$ versus control). At 24 hours median Tarlov scores were $0,2.5(P=.0002)$, and $4(P=.0002)$, respectively. Finally, at both 36 and 48 hours median Tarlov scores were 0, 3 ( $P=$.0006), and $4(P=.0002)$, respectively. Conclusion: Memantine significantly reduced neurologic injury related to spinal cord ischemia and reperfusion after aortic occlusion. (J Thorac Cardiovasc Surg 1999;117:285-91)
$D$ r araplegia caused by ischemic injury or postischemic reperfusion injury remains an unpredictable complication after operations on the descending thoracic or

From the Departments of Cardiothoracic Surgery, ${ }^{\mathrm{a}}$ Anesthesiology, Histology, ${ }^{\mathrm{c}}$ and Neurophysiology, ${ }^{\mathrm{d}}$ University of Vienna, Vienna, Austria.

This work was supported by grant 5713 from the Austrian National Bank and by Dr H. Kolassa and Merz, Vienna, Austria.

Read at the Seventy-eighth Annual Meeting of The American Association for Thoracic Surgery, Boston, Mass, May 3-6, 1998.

Received for publication May 8, 1998; revisions requested Aug 6, 1998; revisions received Sept 18, 1998; accepted for publication Oct 8, 1998.

Address for reprints: Marek Ehrlich, MD, Department of CardioThoracic Surgery, Mount Sinai Medical Center, One Gustave Levy Place, Box 1028, New York, NY 10029.

Copyright (C) 1999 by Mosby, Inc.

$0022-5223 / 99 \$ 8.00+0 \quad \mathbf{1 2 / 6 / 9 5 1 5 5}$ thoracoabdominal aorta. The incidence of spinal cord complications ranges from $8 \%$ to $30 \%$ and depends on the nature and extent of the disease and the duration of aortic crossclamping or hypothermic circulatory arrest. ${ }^{1,2}$ Little is known about the exact mechanisms of neuronal cell death after spinal cord ischemia, and several attempts have been made experimentally and clinically to minimize or prevent paraplegia after such operations. ${ }^{3-8}$

Evidence is gathering that excitatory amino acid neurotransmission may contribute to neuronal cell death. ${ }^{9,10}$ Glutamate, the most important excitatory amino acid, is potentially toxic to central nervous tissue through activation of postsynaptic $N$-methyl-D-aspartate (NMDA) receptors and the subsequent induction of excessive calcium ion influx, which leads to neuronal cell death. ${ }^{11}$ NMDA antagonists have been proved to reduce spinal cord injury after ischemia. ${ }^{12}$ 
Table I. Neurologic status (Tarlov score) at 12, 24, 36, and 48 hours after aortic occlusion

\begin{tabular}{|c|c|c|c|c|c|c|c|c|}
\hline \multirow[b]{2}{*}{ Group } & \multicolumn{2}{|c|}{$12 \mathrm{~h}$} & \multicolumn{2}{|c|}{$24 \mathrm{~h}$} & \multicolumn{2}{|c|}{$36 \mathrm{~h}$} & \multicolumn{2}{|c|}{$48 h$} \\
\hline & Median & Range & Median & Range & Median & Range & Median & Range \\
\hline Control $(\mathrm{n}=8)$ & 0 & $0-1$ & 0 & $0-1$ & 0 & $0-2$ & 0 & $0-2$ \\
\hline Intra-aortic memantine $(\mathrm{n}=8)$ & $2^{*}$ & $0-3$ & $2.5 \dagger$ & $1-4$ & $3 \ddagger$ & $1-4$ & $3 \neq$ & $1-4$ \\
\hline Systemic memantine ( $\mathrm{n}=8$ ) & $3 \dagger$ & $2-4$ & $4 \dagger$ & $3-4$ & $4 \dagger$ & $3-4$ & $4 \dagger$ & $3-4$ \\
\hline
\end{tabular}

Tarlov score: 0 , No movement; 1 , slight movement; 2 , sits alone; 3, weak hop; 4, normal hop.

$* P=.001$ versus control.

$\dagger P=.0002$ versus control.

$\ddagger P=.0006$ versus control.

Table II. Time for reduction of amplitudes of spinal root-stimulated muscle potentials after crossclamping compared with baseline values taken 1 minute before occlusion of the aorta

\begin{tabular}{|c|c|c|c|c|c|c|c|c|c|}
\hline & \multicolumn{3}{|c|}{ Time until amplitude $<75 \%$ (min) } & \multicolumn{3}{|c|}{ Time until amplitude $<50 \%$ (min) } & \multicolumn{3}{|c|}{ Time until amplitude $<25 \%$ (min) } \\
\hline & Muscle I & Muscle II & Muscle III & Muscle I & Muscle II & Muscle III & Muscle I & Muscle II & Muscle III \\
\hline \multicolumn{10}{|l|}{ Group 1} \\
\hline Median & 13 & 14 & 16 & 23 & 15 & 16 & 26 & 16 & 23 \\
\hline Range & $9-38$ & $2-25$ & $1-28$ & $10-29$ & $9-31$ & $2-30$ & $10-35$ & $14-37$ & $16-40$ \\
\hline \multicolumn{10}{|l|}{ Group 2} \\
\hline Median & 18 & 15 & 13 & 19 & 16 & 14 & 23 & 19 & 16 \\
\hline Range & $7-36$ & $1-40$ & $5-27$ & $9-24$ & $1-40$ & $5-33$ & $11-26$ & $1-40$ & $5-40$ \\
\hline \multicolumn{10}{|l|}{ Group 3} \\
\hline Median & 18 & 14 & 14 & 19 & 14 & 15 & 22 & 15 & 20 \\
\hline Range & $1-26$ & $9-18$ & $5-18$ & $15-29$ & $10-23$ & $6-21$ & $15-35$ & $11-21$ & $8-30$ \\
\hline
\end{tabular}

Muscle I, Superficial gluteal muscle; Muscle II, quadriceps muscle of the thigh; Muscle III, biceps muscle of the thigh; Group 1, control ( $=8$ ); Group 2, animals treated with memantine infusion during aortic crossclamping $(\mathrm{n}=8)$; group 3 , animals treated with systemic memantine infusion before crossclamping $(\mathrm{n}=8)$. No statistically significant difference was found between groups $(P>.9)$ or between muscles $(P=.14)$

The noncompetitive NMDA receptor antagonist memantine is known to attenuate hypoxic or ischemic damage to spinal neurons. ${ }^{13}$ This study elucidates the effect of memantine on the neurologic outcome of spinal cord ischemia and reperfusion injury related to aortic occlusion in the rabbit model. The rabbit was used because of its unique segmental arterial blood supply to the spinal cord from the infrarenal aorta. ${ }^{14}$ The primary interest was to compare each treated group with the control group.

\section{Materials and methods}

All animals received humane care in compliance with the "Guide for the Care and Use of Laboratory Animals" prepared by the Institute of Laboratory Animal Resources and published by the National Institutes of Health (NIH Publication No. 85-23, revised 1985) and "Guidelines for Animal Experiment," Vienna University Hospital.

Twenty-four New Zealand White rabbits (3.4-4.3 kg) were randomly split into 3 groups. In the control group of 8 animals (group 1), crossclamping of the infrarenal aorta was performed without intervention. In 8 rabbits (group 2) a 24gauge catheter was inserted into the aorta distal to the proximal clamp and memantine was infused with an infusion pump $(20 \mathrm{mg} / \mathrm{kg}$ memantine in $15 \mathrm{~mL}$ sodium chloride at 5 $\mathrm{mL} / \mathrm{min}$ ) into the isolated aortic segment. After the infusion the aortic catheter was removed and the arteriotomy was closed with a 7-0 polypropylene suture. The third group included 8 animals (group 3) that were treated with a systemic memantine infusion $(20 \mathrm{mg} / \mathrm{kg}$ memantine in $30 \mathrm{~mL}$ sodium chloride at $1 \mathrm{~mL} / \mathrm{min}$ ) 45 minutes before aortic occlusion. All animals were anesthetized intramuscularly with 25 $\mathrm{mg} / \mathrm{kg}$ ketamine, $2.5 \mathrm{mg} / \mathrm{kg}$ xylazine, and $0.06 \mathrm{mg} / \mathrm{kg}$ atropine.

After intubation, controlled ventilation (Servo 900; Siemens-Elema, Solna, Sweden) was started with $8 \mathrm{~mL} / \mathrm{kg}$ of $50 \%$ oxygen mixed with air at a respiratory rate of 30 breaths/min. Ketamine was infused at a rate of 4 to $6 \mathrm{mg}$. $\mathrm{kg}^{-1} \cdot \mathrm{h}^{-1}$ during the operation and was discontinued immediately after the procedure. An arterial line was placed in an ear artery through a 22-gauge catheter for on-line monitoring of arterial blood pressure. Arterial blood $\mathrm{Po}_{2}, \mathrm{PCO}_{2}, \mathrm{pH}$, bicarbonate concentration, hemoglobin concentration, and hematocrit were measured every 15 minutes for the purpose of adjusting ventilation to maintain a $\mathrm{PCO}_{2}$ of $36 \pm 6 \mathrm{~mm} \mathrm{Hg}$. Blood pressure, electrocardiogram, and rectal temperature were recorded digitally (Hellige/Biosys, Vienna, Austria) during the intervention. A heating pad was used on each animal to maintain normal body temperature. 
Table III. Time for increase of amplitudes of spinal root-stimulated muscle potentials after release of crossclamp compared with baseline values taken 1 minute before occlusion of the aorta

\begin{tabular}{|c|c|c|c|c|c|c|c|c|c|}
\hline & \multicolumn{3}{|c|}{ Time until amplitude $>25 \%$ (min) } & \multicolumn{3}{|c|}{ Time until amplitude $>50 \%$ ( $\mathrm{min}$ ) } & \multicolumn{3}{|c|}{ Time until amplitude $>75 \%$ (min) } \\
\hline & Muscle I & Muscle II & Muscle III & Muscle I & Muscle II & Muscle III & Muscle I & Muscle II & Muscle III \\
\hline \multicolumn{10}{|l|}{ Group 1} \\
\hline Median & 25 & 12 & 17 & 19 & 39 & 19 & 22 & 31 & 22 \\
\hline Range & $25-34$ & $1-27$ & $3-18$ & $9-28$ & $4-47$ & $1-23$ & $4-39$ & $25-33$ & $4-29$ \\
\hline Potentials* & 3 & 3 & 7 & 3 & 3 & 6 & 3 & 3 & 4 \\
\hline Animals $\dagger$ & 8 & 8 & 8 & 7 & 7 & 7 & 5 & 5 & 5 \\
\hline \multicolumn{10}{|l|}{ Group 2} \\
\hline Median & 12 & 5 & 7 & 17 & 15 & 19 & 17 & 24 & 17 \\
\hline Range & $4-40$ & $3-26$ & $1-10$ & $14-19$ & $3-30$ & $3-24$ & $17-17$ & $3-35$ & $10-27$ \\
\hline Potentials* & 5 & 4 & 5 & 4 & 4 & 4 & 1 & 3 & 3 \\
\hline Animals $\dagger$ & 6 & 6 & 6 & 6 & 6 & 6 & 1 & 3 & 3 \\
\hline \multicolumn{10}{|l|}{ Group 3} \\
\hline Median & 3 & 4 & 5 & 7 & 22 & 12 & 8 & 17 & 15 \\
\hline Range & $1-11$ & $2-18$ & $2-8$ & $1-26$ & $18-28$ & $4-27$ & $1-15$ & $17-17$ & $2-28$ \\
\hline Potentials* & 5 & 5 & 4 & 4 & 3 & 3 & 3 & 1 & 3 \\
\hline Animals $\dagger$ & 7 & 7 & 7 & 6 & 6 & 6 & 4 & 1 & 4 \\
\hline
\end{tabular}

Muscle I, Superficial gluteal muscle; Muscle II, quadriceps muscle of the thigh; Muscle III, biceps muscle of the thigh; Group 1, control; Group 2, animals treated with memantine infusion during aortic crossclamping; group 3, animals treated with systemic memantine infusion before crossclamping.

*Number of potentials that were recorded.

$†$ Number of animals.

Motor evoked potentials. Two needle electrodes of an electric stimulator (Digitimer A, Welwyn Garden City, United Kingdom) for transcranial stimulation were fixed into the scalp on the dorsum of the nose and the midline over the occiput (anode). Additional electrodes of a second stimulator (Digitimer) for spinal stimulation were placed into 2 dorsal muscles on the left side close to lumbar vertebra 4 and spinal vertebra 3. A 4-channel electromyograph (Viking IV, Nicolet, Madison, Wis) was prepared for simultaneous recording of compound muscle action potentials from the superficial gluteal muscle, quadriceps muscle of the thigh, and biceps muscle of the thigh. Two separate single-impulse stimulations $(150 \mu \mathrm{s})$ were released every minute, starting 2 minutes before crossclamping and ending when anesthesia was finished. Output levels for single-impulse stimulation up to 160 $\mathrm{V}$ for transcranial stimulation and $70 \mathrm{~V}$ for spinal stimulation were sufficient to achieve supramaximal stimulus; resulting amperage was 50 to $150 \mathrm{~mA}$. Intervals for amplitude change (decrease or increase) by $75 \%, 50 \%$, and $25 \%$ (with respect to the size of amplitudes gained 1 minute before crossclamping) were evaluated.

After sterile preparation a median laparotomy was made. The abdominal aorta was mobilized inferiorly to the left renal vein and down to the bifurcation. Each rabbit had anticoagulation with heparin (100 units/kg) before crossclamping. Aortic occlusion was obtained by placement of a vascular clamp above the aortic bifurcation followed by clamping of the aorta just below the left renal vein. All animals were subjected to 40 minutes of crossclamp time. Memantine was obtained from Merz (Dr H. Kolassa and Merz, Vienna, Austria).

After 40 minutes, the crossclamps were released and the laparotomy incision was closed. The animals were allowed to recover. Neurologic status was assessed with the Tarlov score ( 0 , no movement; 1 , slight movement; 2 , sits alone; 3 , weak hop; 4, normal hop) at 12, 24, 36, and 48 hours after the operation by an observer who had no previous knowledge of the experimental protocol. ${ }^{15}$

All animals were killed 48 hours after the operation with a lethal injection of pentobarbital.

Histopathologic studies. All histopathologic materials were examined by a neuropathologist (P.B.) who was blinded both to the experimental design and to the identity of all animals. Excised segments of the vertebral column were fixed by immersion in 5\% neutralized formalin. The spinal medulla was dissected and specimens were divided into central and external segments. Alcohol dehydration and paraffin embedding were performed with a Tissue-Tek 2000 (Miles Laboratories, Mishawaka, Ind) embedding device. Sections were cut $5 \mu \mathrm{m}$ thick and stained with hematoxylin and eosin. Classification and quantification of anterior horn motor neurons were done in sections stained with hematoxylin and eosin. Perikarya were defined and counted and their frequencies were compared between the groups. The following morphologic criteria were used to define 4 groups of neurons: (1) In neurons with normal morphologic characteristics, perikarya are polygonal with cytoplasmic extensions. Centrally positioned nuclei are round, well defined, with loosely textured chromatin and prominent nucleolus. The cytoplasm stains violet; it contains ample Nissl substance as clumps of basophilic material. (2) In neurons with pyknosis, cytoplasm of pyknotic motor neurons is condensed and clefts separate the shrunken perikarya from the adjoining neuropil. Nuclei are reduced in size and irregularly outlined. The cytoplasm of pyknotic neurons is hyperchromatic, and its color- 


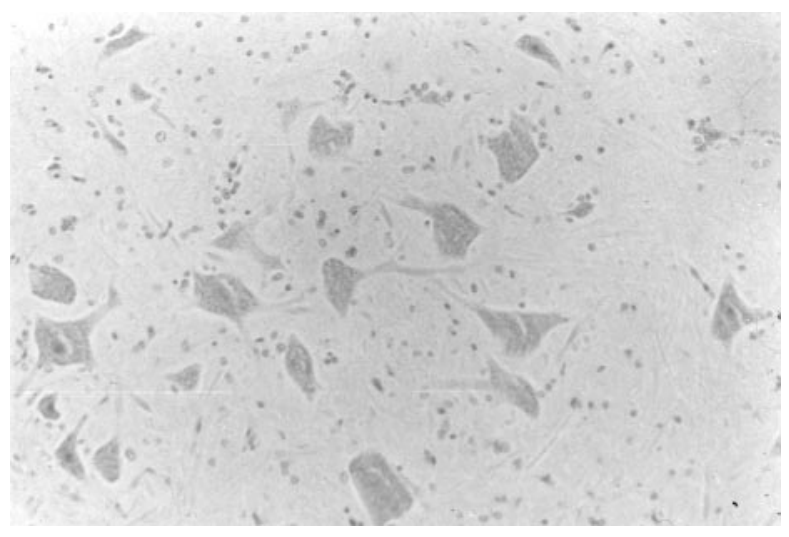

Fig 1. Cross section of the lumbar spinal cord in an animal treated with memantine. Well-preserved, normal-looking motor neurons are seen. Perikarya are polygonal with cytoplasmic extensions. The cytoplasm stains violet; it contains ample Nissl substance as clumps of basophilic material.

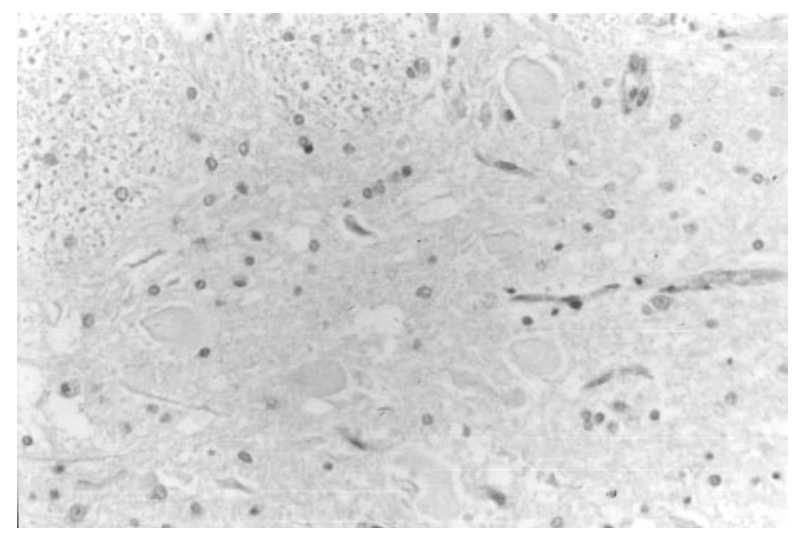

Fig 2. Cross section of the lumbar spinal cord in a control animal. Edema and vacuolization are prominent in anterior horn motor neurons. Cellular shape is ovoid to round, and Nissl substance is highly dispersed or no longer present.

Table IV. Frequencies of intact and injured anterior horn motor neurons after 40 minutes of aortic crossclamping

\begin{tabular}{|c|c|c|c|c|c|c|c|c|}
\hline \multirow[b]{2}{*}{ Group } & \multicolumn{2}{|c|}{$\operatorname{Normal}(\%)$} & \multicolumn{2}{|c|}{ Pyknotic (\%) } & \multicolumn{2}{|c|}{ Chromatolytic (\%) } & \multicolumn{2}{|c|}{ Vacuolization (\%) } \\
\hline & Median & Range & Median & Range & Median & Range & Median & Range \\
\hline Control $(\mathrm{n}=8)$ & 36 & $8-54$ & 17.5 & $8-31$ & 28 & $13-46$ & 12 & $0-38$ \\
\hline Intra-aortic memantine $(\mathrm{n}=8)$ & $69.5^{*}$ & $51-82$ & 15.5 & $4-25$ & 14.5 & $8-25$ & $1 \dagger$ & $0-7$ \\
\hline Systemic memantine $(\mathrm{n}=8)$ & $63.5^{*}$ & $50-71$ & 16 & $8-24$ & 23 & $8-32$ & 0 & $0-0 \ddagger$ \\
\hline
\end{tabular}

$* P<.001$ versus control.

$\dagger P=.015$ versus control.

$\ddagger P=.002$ versus control.

ing changes to eosinophilic. (3) In neurons with chromatolysis, the perikaryon of chromatolytic motor neurons appears enlarged, ovoid rather than polygonal in shape. Cytoplasmic staining of these neurons is significantly reduced, causing an overall pale appearance. (4) In neurons with vacuolization, cellular shape is ovoid to round and Nissl substance is highly dispersed or not present. In addition, the nucleus is heavily disintegrated and largely devoid of chromatin.

Statistical analysis. Values are expressed as mean and SD or as the median and range. The differences among groups in Tarlov scores and in quantitative histologic findings were tested by nonparametric statistical analysis with the MannWhitney $U$ test. Evoked potential data were analyzed with repeated measurement analysis of variance on the log-transformed data.

\section{Results}

All animals survived the procedure and were included in the study. Differences among groups were not found with respect to preoperative status, weight, temperature, and heart rate. Control animals were paraplegic with median Tarlov scores of 0 at all observation points. One animal had a Tarlov score of 1 after 12 hours and improved to a score of 2 at 36 and 48 hours. Twelve hours after the procedure, group 2 animals had a median Tarlov score of 2, and 6 of 8 animals improved to scores of 3 and 4 at 48 hours (median 3). Preoperative systemic infusion of memantine in group 3 was associated with full recovery (Tarlov score 4) in 6 animals at 36 and 48 hours, with only 2 animals reaching a score of 3 at the last 2 observation points. Neurologic statuses at all 4 observation points are depicted in Table I.

Motor evoked potentials. Transcranial evoked compound muscle action potentials showed changes in amplitudes before, during, and after crossclamping, depending on the depth of anesthesia, and did not seem useful for comparisons among the 3 groups. Most of these amplitudes decreased at varied intervals, ranging from a few minutes to the entire duration of crossclamping. When a bolus of anesthetic was given, compound muscle action potentials disappeared. Spinal evoked compound muscle action potentials of the 
lower limb muscles did not depend on anesthetic concentration. During crossclamping all amplitudes decreased continuously, with no correlation in intervals between the control animals and the treated groups (Table II). Data on all observed sedated animals (6-8 animals until amplitude $>25 \%, 6-7$ animals until amplitude $>50 \%$, and 1-5 animals until amplitude $>75 \%$ ) indicate that both memantine groups regained some activity of their potentials earlier than did the control group after release of the clamp. Intervals for increase of amplitude values by $25 \%, 50 \%$, and $75 \%$ with respect to baseline values gained 1 minute before crossclamping are depicted in Table III.

Histologic examination. When comparing anterior horn, a predominance of well-preserved motor neurons was found in groups 2 and 3, with only a few injured neurons (Fig 1, Table IV). Edema and vacuolization were prominent in animals to which no pharmacologic intervention had been applied (Fig 2).

\section{Discussion}

Spinal cord injury and resultant paraplegia can be devastating sequelae of operations on the descending thoracic aorta. Despite various surgical and pharmacologic efforts to minimize this complication, no method has completely prevented the development of paraplegia. It appears that the cause of this complication is multifactorial and includes prolonged duration of ischemia, interruption of critical intercostal and lumbar arteries, decrease in spinal cord perfusion pressure, and postoperative reperfusion injury. ${ }^{16,17}$ There is evidence that excitatory amino acid neurotoxicity may play a role in neuronal injury after ischemia. ${ }^{9}$ Glutamate and aspartate are 2 of these excitatory amino acid neurotransmitters. They bind to NMDA receptors, which are abundant in the spinal cord. ${ }^{18}$ When stimulated the NMDA receptors open a cation channel, allowing the influx of calcium and sodium. Under physiologic circumstances, protective mechanisms limit neuronal glutamate exposure and prevent toxicity. During hypoxia energy failure disturbs ion hemostasis in the context of glutamate accumulation. This accumulation may cause neuronal overreaction and cell death. Pharmacologic blockade of these receptors has been shown to decrease spinal cord injury. ${ }^{19}$

This study demonstrates the efficacy of memantine in reducing the neurologic injury associated with prolonged aortic occlusion. The neuroprotective potency of this drug is presumably attributable to its ability to block calcium ion entry into the cell. ${ }^{20}$

There was significant improvement in the clinical outcomes of rabbits that received memantine with respect to the control group. Both treated groups had higher Tarlov scores than did the control animals. Six of 8 animals treated with memantine before the operation had $100 \%$ recovery at 48 hours. These animals were standing without difficulty and were hopping normally. Animals that received intra-aortic memantine injections reached a median Tarlov score of 3 after 48 hours, without standing problems but with weak hopping. In contrast, control animals were paraplegic during the entire observation interval. Our results confirm the findings of Keilhoff and colleagues ${ }^{21}$ that memantine is probably most efficient when applied before surgical intervention.

Histologic examination confirmed the ability of memantine to limit neuronal necrosis in the anterior horn motor neurons. Ischemia of the spinal cord in this experiment caused perikaryal swelling and vacuolization of anterior horn motor neurons. These morphologic changes developed after ischemia and caused the physiologic and clinical consequences observed after ischemic disturbance. Chromatolysis of Nissl substance, swelling and vacuolization of perikarya, and karyolysis were more frequently seen in the control group than in either group of treated animals, and these control animals showed severe functional impairment.

For monitoring nerve conductance ability, cortical somatosensory evoked potentials and different kinds of motor evoked potentials have been used as an additional method of detecting ischemia in an early and reversible stage to allow application or adjustment of protective strategies. Somatosensory evoked potentials are conducted mainly in the ascending sensory tracts of the posterior columns. Because the anterior horn motor neurons are especially sensitive to ischemia and receive their blood supply mainly from the anterior spinal artery, whereas the posterior columns are supplied through the posterior spinal artery, somatosensory evoked potentials may not always reflect ischemia of the motor system. ${ }^{22}$ In our study spinal root stimulation potentials and transcranial motor evoked potentials were used. The latter showed gradual decrease under aortic occlusion but instant loss of amplitude when a bolus of ketamine, with or without xylazine, was administered. Our findings of various myogenic responses of transcranial motor evoked potentials depending on anesthesia depth is confirmed by other studies, which showed amplitudes of both transcranial motor evoked potentials and somatosensory evoked potentials to be affected by anesthetics. ${ }^{23}$

Spinal root stimulation was associated with stable measurement conditions, allowing comparison of treatment groups with the control animals. Differences in 
times for reduction in amplitude during ischemia were not found among the 3 groups, indicating that loss of these recorded potentials did not reflect postoperative neurologic outcome. After release of the aortic crossclamp there was a trend in which both treated groups regained activity somewhat earlier than did the control group. Animals were only stimulated until the point at which they started to awake, however, so not all animals were included in this observation. This limitation precluded statistical analysis of these potentials. Further clinical investigations are required to determine the beneficial effects of memantine in preventing spinal cord injury after operations on the descending aorta. This NMDA blocker might be of interest because it is clinically used for the therapy of various cerebral disorders, such as Parkinson disease, spasticity, and chronic brain syndrome. ${ }^{24}$

In conclusion, memantine significantly reduces the neurologic injury related to spinal cord ischemia. Although extrapolating the results to human beings is premature, systemic infusion of memantine may prove to be a simple yet effective means of spinal cord protection in descending thoracic and thoracoabdominal aneurysm repair.

\section{REFERENCES}

1. Svenson LG, Crawford ES, Hess KR, Coselli JS, Safi HJ. Experience with 1509 patients undergoing thoracoabdominal aortic operations. J Vasc Surg 1993;17:357-70.

2. Hollier LH, Money SR, Naslund TC, et al. Risk of spinal cord dysfunction in patients undergoing thoracoabdominal aortic replacement. Am J Surg 1992:164:210-4.

3. Kazui T, Komatsu S, Yokoyama H. Surgical treatment of aneurysms of the thoracic aorta with the aid of partial cardiopulmonary bypass: an analysis of 95 patients. Ann Thorac Surg 1987;43:622-7.

4. Hill AB, Kalman PG, Johnston KW, Vosu HA. Reversal of delayed-onset paraplegia after thoracic surgery with cerebrospinal fluid drainage. J Vasc Surg 1994;20:315-7.

5. Galla JD, Ergin MA, Sadeghi AM, Lansman SL, Danto J, Griepp RB. A new technique using somatosensory evoked potential guidance during descending and thoracoabdominal aortic repairs. J Card Surg 1994;9:662-72.

6. Granke K, Hollier LH, Zdrahal P, Moore W. Longitudinal study of cerebral spinal fluid drainage in polyethylene glycol-conjugated superoxide dismutase in paraplegia associated with thoracic aortic cross-clamping. J Vasc Surg 1991;13:615-21.

7. Laschinger JC, Cunningham JN Jr, Cooper MM, Krieger K, Nathan IM, Spencer FC. Prevention of ischemic spinal cord injury following aortic cross-clamping: use of corticosteroids. Ann Thorac Surg 1984;38:500-7.

8. De Mol B, Hammerlijnck R, Janssen T, Jageneau A. Infrarenal aortic occlusion in the rabbit to assess the effect of flunarizine in the prevention of ischemic spinal cord injury. Thorac Cardiovasc Surg 1991;39:36-9.
9. Rokkas CK, Helfrich LR, Lobner DC, Choi DW, Kouchoukos NT. Dextrorphan inhibits the release of excitatory amino acids during spinal cord ischemia. Ann Thorac Surg 1994;58:312-20.

10. Rothman SM, Olney JW. Glutamate and the pathophysiology of hypoxic-ischemic brain damage. Ann Neurol 1986;19:105-11.

11. Choi DW, Maulucci-Gedde M, Kriegstein AR. Glutamate neurotoxicity in cortical cell culture. J Neurosci 1987;7:357-68.

12. Choi DW. Glutamate neurotoxicity and diseases of the nervous system. Neuron 1988;1:623-34.

13. El Nasr MS, Peruche B, Rossberg C, Mennel HD, Krieglstein J. Neuroprotective effect of memantine demonstrated in vivo and in vitro. Eur J Pharmacol 1990;185:19-24.

14. Moore WM, Hollier LH. The influence of severity of spinal cord ischemia in the etiology of delayed-onset of paraplegia. Ann Surg 1991:213:427-33.

15. Tarlov IM. Spinal cord compression: a mechanism of paralysis and treatment. Springfield (IL): Charles C Thomas, 1957. p. 147.

16. Grubbs PE Jr, Marini C, Toporoff B, et al. Somatosensory evoked potentials and spinal cord perfusion pressure are significant predictors of postoperative neurologic dysfunction. Surgery 1988;104:216-23.

17. Crawford ES, Crawford JL, Safi HJ, et al. Thoracoabdominal aortic aneurysms: preoperative and intraoperative factors determining immediate and long-term results of operations in 605 patients. J Vasc Surg 1986;3:389-404.

18. Jansen KLR, Faull RLM, Dragunow M, Waldvogel H. Autoradiographic localization of NMDA, quisqualate and kainic acid receptors in human spinal cord. Neurosci Lett 1990;108:53-7.

19. Kemp JA, Foster AC, Wong EHF. Non-competitive antagonists of excitatory amino acid receptors. Trends Neurosci 1987;10:294-8.

20. Bormann J. Memantine is a potent blocker of $N$-methyl-D-aspartate (NMDA) receptor channels. Eur J Pharmacol 1998;166:591-2.

21. Keilhoff G, Wolf G. Memantine prevents quinolic acid-induced hippocampal damage. Eur J Pharmacol 1992;219:451-4.

22. Zornow M, Grafe MR, Tybor C, Swenson M. Preservation of evoked potentials in a case of anterior spinal artery syndrome. Electroencephalogr Clin Neurophysiol 1990;77:137-9.

23. Ghaly RF, Stone LJ, Aldrete JA, Levy WJ. Effects of incremental ketamine hydrochloride doses on motor evoked potentials (MEPs) following transcranial magnetic stimulation: a primate study. J Neurosurg 1990:2:79-85.

24. Schneider E, Fischer R, Clemens F, Balzereit EW, Fünfgeld R, Haase HJ. Effects of oral memantine administration on Parkinson symptoms: results of a placebo-controlled multicenter study. Dtsch Med Wochenschr 1984;109:987-90.

\section{Discussion}

Dr Edward D. Verrier (Seattle, Wash). Can you go into more detail on the role of excitatory amino acids in ischemiareperfusion injury? Is this phenomenon exclusive to neural tissue, for instance? What is the molecular mechanism; how does it work? Does it affect transcription or translation at the molecular level, or is it effective by changing calcium?

Dr Ehrlich. It is a complex cascade when spinal cord ischemia is induced. First the ischemia initiates the release of excitatory amino acids, such as glutamate, aspartate, and glycine, from axons into the extracellular space. Postsynaptic NMDA receptors, especially for the amino acid glutamate, are activated. As a consequence, calcium channels are opened 
that further activate a series of enzymes, leading eventually to neuronal cell death.

Dr Pedro J. del Nido (Boston, Mass). One of the mechanisms through which delayed neuronal injury occurs is apoptosis, and that can occur 48 to 72 hours after the original insult. Did you look for evidence that this might actually be occurring in the spinal cord tissue? Also, did you actually look for glutamate concentration in the spinal cord fluid?

Dr Ehrlich. No, in this study we did not look specifically at apoptosis as a mechanism of cell death. I am aware that there is growing evidence, especially from Dr Kouchoukos' group, that apoptosis is among the mechanisms of delayed programmed cell death. With respect to glutamate concentrations in the spinal cord, it was difficult to obtain liquid from the spine in this animal model.

Dr Tadashi Omoto (Boston, Mass). Maybe it was 3 years ago in The Annals of Thoracic Surgery that a Japanese researcher from Fukuoka University reported on aortic crossclamping as long as 24 hours before, providing a late window on the preconditioning side of aortic crossclamping. Is this the same mechanism of excitatory amino acids? The research background was that before 24 hours after the aortic crossclamping of the descending aorta they showed improvement of the paraplegia. Do you think this mechanism will be similar to the excitatory amino acid cascade you described?
Dr Ehrlich. I cannot comment on this. We know from recent studies that there is an increase in all excitatory amino acids shortly after aortic occlusion. I am unsure of the influence preconditioning of the spinal cord could have on the release of glutamate.

Dr Fred A. Crawford, Jr (Charleston, SC). You had 2 experimental groups, 1 in which memantine was administered intra-aortically and 1 in which it was administered systemically. Is there any possibility that the 2 routes of administration could be additive, if the drug were to be given both ways at the same time?

Dr Ehrlich. Such a form of application could possibly be more powerful in preventing spinal cord ischemia.

Dr Tatu Juvonen (Oulu, Finland). I have a question regarding this molecule. Most of those glutamate receptor blockers are known to be extremely neurotoxic and to have serious side effects in clinical use. With respect to memantine, are there any potential concerns about clinical use?

Dr Ehrlich. I think that this is an important question because most of the excitatory amino acid blockers used so far, such as dextrorphan and MK-801, are neurotoxic in higher doses. Memantine, however, is already clinically used today in many countries as an antiparkinsonian drug. This drug is therefore of enormous interest with respect to clinical application for the future.

\section{Availability of Journal back issues}

As a service to our subscribers, copies of back issues of The Journal of Thoracic and Cardiovascular Surgery for the preceding 5 years are maintained and are available for purchase from Mosby at a cost of $\$ 17.00$ per issue until inventory is depleted. The following quantity discounts are available: $25 \%$ off on quantities of 12 to 23, and one third off on quantities of 24 or more. Please write to Mosby, Inc, Subscription Services, 11830 Westline Industrial Drive, St Louis, MO 63146-3318, or call 800-453-4351 or 314-453-4351 for information on availability of particular issues. If unavailable from the publisher, photocopies of complete issues may be purchased from UMI, $300 \mathrm{~N}$ Zeeb Rd, Ann Arbor, MI 48106, 313-761-4700. 